Piotr SŁONIMSKI.

W sprawie występowania wrotków z rodzaju Keratella Bory de St. Vincent na Polesiu.

[3 rys. w tekście].

Über das Auftreten von Rotatorien aus der Gattung Keratella Bory de St. Vincent in Polesien.

[mit 3 Fig. im Text,.

Jak to zaznaczyłem poprzednio (Fragm. Faunist. Mus. Zoologici Polon. T. I, № 11, 1931), Polesie stanowi teren bardzo bogaty i ciekawy pod względem fauny wrotków (Rotatoria).

Do podobnego wniosku doszedł niedawno i J. Wiszniew$\mathrm{ski}^{1}$ ), a to na zasadzie opracowania materjałów, zebranych przez uczestników wyprawy poleskiej, zorganizowanej w sierpniu 1929 roku przez Instytut im. M. Nenckiego. Poszukiwania jednak faunistyczne Wiszniewskiego, podobnież jak i jego poprzednika N. Voronkova ${ }^{2}$, nie wyczerpały nawet w części „tego ciekawego i zasługującego na dalsze studja tematu“ (por. J. W is zni ew sk i, 1930, str. 280).

Przyczynek niniejszy oparty jest na opracowaniu części materjałów, zgromadzonych przeze mnie, jako uczestnika wycieczki zoologicznej na Polesie, zorganizowanej przez Komisję Fizjograficzną Polskiego Towarzystwa Krajoznawczego w lecie 1913 (lipiec-sierpień) ${ }^{3}$ ). Niechaj mi będzie wolno złożyć na tem miej-

1) Wiszniewski, J. Przyczynek do znajomości fauny wrotków Polesia. Archiwum Hydrobiologji i Rybactwa, T. V, № 3-4, 1930.

2) Voronkov, N. V. K faunie Rotatoria Minskoj gubern. Trudy Stud. Kružka Izslied. Russk. Prirody, T. 4, pp. 121-133, 1909.

$\left.{ }^{3}\right)$ Uczestnikami tej wycieczki byli: P. J. D o mani ewski, M. Gedroyć, K. Kul wieć, J. Mydlarski, P. Słonimski. 
scu me szczere podziękowanie Pp. Wojciechostwu hr. Pusłowskim za nader serdeczną gościnę i szereg ułatwień w czasie pobytu mego w Zawiszczu.

W przyczynku niniejszym uwzględniam przedstawicieli jednego tylko rodzaju, a mianowicie Keratella Bory de St. Vincent, $1822^{4}$ ), stwierdzonych przezemnie w szeregu próbek, pochodzących $z$ rzeki Piny, kanału Ks. Ogińskiego i z jeziora Wyganowskiego. Wiadomo bowiem, iż badania wód płynących należą w hydrobiologji do zadań, stosunkowo nowych, a u nas są dopiero w zaczątku. $Z$ jezior uwzględnione zostało tylko jezioro Wyganowskie, gdyż łączy się ono bezpośrednio z Kanałem Ogińskiego ${ }^{5}$ ). Wrotki $\mathrm{z}$ rodzaju Keratella Bory de St. Vincent należą do form szeroko rozpowszechnionych i wykazujących wyraźną zmienność sezonową. Jest rzeczą znaną, iż opierając się na zmienności przedstawicieli tego właśnie rodzaju, La utenborn ${ }^{6,7}$ ) wprowadził do nauki pojęcie „kręgu form“ lub "szeregów zmienności“ („Formenkreis - Variationsreihe“). Mając do mej dyspozycji materjał poleski $\mathrm{z}$ jednego tylko sezonu letniego (lipiec-sierpień), nie mogę szerzej uwzględnić poszukiwań La ute n born'a i jego następców, wiążących się z ogólnemi zagadnieniami nauki o zmienności organizmów. Ograniczę się więc do zestawienia znalezionych przeze mnie przedstawicieli rodzaju $K e$ ratella Bory de St. Vincent i przytoczenia niektórych danych z dostępnego mi piśmiennictwa, obejmującego zagadnienia systematyczno-ekologiczne w obrębie wyróżnionych przeze mnie form.

4) Zgodnie $\mathrm{z}$,Synopsis of the Rotatoria* H a r ring'a (Bull. Unit. Stat. Nat. Mus., 81, 1913) nazywam rodzaj ten Keratella, a nie Anuraea.

5) Kanał Ogińskiego składa się z dwóch części, biegnących od jeziora Wyganowskiego: części północnej (krótszej) i południowej (znacznie dłuższej).

$\left.{ }^{6}\right)$ La utenborn, R. Der Formenkreis von Anuraea cochlearis. I. Verhandl. d. Naturhist.-Med. Vereins Heidelberg. N. F. Bd. VI (1900), pag. $412-448$.

7) L a u t e n born, R. Der Formenkreis von Anuraea cochlearis. II T. Die cyklische oder temporale Variation von Anuraea cochlearis. Verhandl. d. Naturhist.-Mediz. Vereins Heidelberg. N. F. Bd. VII (1903), pag. 529-621. 


\section{Keratella cochlearis ( $\mathrm{G}$ o s s e).}

1851. Anuraea cochlearis Go s s e, Ann. Mag. Nat. Hist. ser. 2, T. 8, str. 202.

1913. Keratella cochlearis $\mathrm{H}$ a r ring, Bull. Unit. Stat. Nat. Mus., vol. 81. p. 56. 1918. Anuraea cochlearis We be $\mathrm{r}$ et Mon te t, Cat. d. Rot. p. 83.

Wrotek ten, uważany przez niektórych autorów (Zschokke, Brehm i inni) za formę północno-lodowcowego pochodzenia, należy do najbardziej rozpowszechnionych nietylko w naszym kraju, lecz prawie że na całej kuli ziemskiej (por. Wierzejski ${ }^{8}$ ) str. 256, Bloedorn ${ }^{9}$ ). Na ziemiach naszych, jeżeli chodzi o wody płynące, Keratella cochlearis (Gosse) była już wielokrotnie notowaną, a mianowicie $w$ Jasiołdzie, Niemnie i jego dopływach przez Voronkova ${ }^{2} i^{10}$ ), w Bugu przez Jakubskieg $0^{11}$ ), w Wiśle pod Gdańskiem przez Lucks'a ${ }^{12}$ ), w Pinie, Jasiołdzie i Prypeci przez Wiszniewskiego (1930).

W moim materjale Keratella cochlearis (Gosse) występowała w próbkach, pochodzących z następujących miejsc połowu: Pina (za Konczycami), środek rzeki

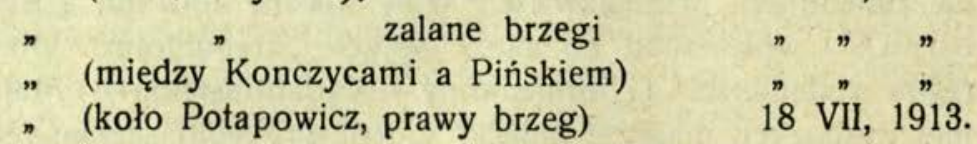

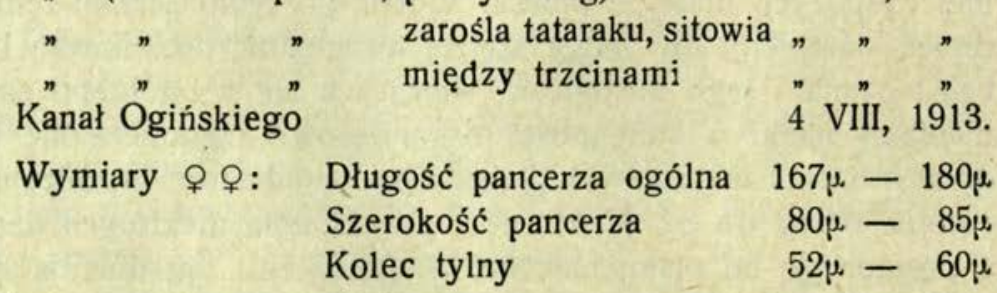

$\left.{ }^{8}\right)$ Wierzejski, A. Rotatoria (wrotki) Galicyi. Rozprawy Wydz. mat.przyr. Akad. Umiej. w Krakowie, T. 26 (1893), str. 160-265.

9) Blo edorn, J. OUber die Rädertierfauna der Provinz Posen. Ber. d. Kön. Fried. Wilhelm. Gymnasium, Poznań, 1912.

$\left.{ }^{10}\right)$ Vor onkov, N. Kołovratki, sobrannyja ekspediciej otdieła Ichtiołogji v Zapadnyj kraj (Vilenskaja, Grodnienskaja i Kovienskaja gub.). 1907. Odbit ka.

11) Jakubski, A. Opis fauny wrotków (Rotatoria) powiatu Sokalskieg, z uwzględnieniem gromad brzuchorzęsków (Gastrotricha) i niesporczaków (Tardigrada). Rozpr. i Wiad. z Muz. im. Dzieduszyckich, t. I, z. 3-4, 1915.

${ }^{12)}$ L u cks, R. Zur Rotatorienfauna Westpreussens, her. vom Westpr Botan.-Zoolog. Verein, Danzig, 1912. 
Według Huber'a ${ }^{13}$ ) osobniki zimowe są naogół większe od form letnich.

2. Keratella cochlearis (Gosse) var. macracantha

f. microcantha $\mathrm{L}$ a ut e $\mathrm{n}$ born.

1900. Anuraea cochlearis var. macracantha f. microcantha La u te n born Verh. Naturhist,-Med. Ver. Heidelberg N. F. T. 6.

Forma ta, o ile mi wiadomo, nie była jeszcze wyróżniona w Polsce. Spotykałem ją w niewielkiej ilości egzemplarzy w rzece Pinie, w materjale pochodzacym ze środka rzeki z dnia '10. VII 1913.

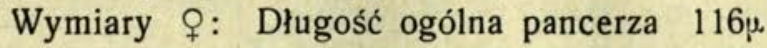
Szerokość pancerza $60 \mu$ Kolec tylny $14 \mu$

Wymiary te, wobec wielkiej zmienności wrotków z tego rodzaju, maja wartość tylko ograniczoną.

3. Keratella cochlearis ( $\mathrm{G}$ os se) var. tecta ( $\mathrm{G}$ os s e). 1851. Anuraea tecta Goss e, Ann. Mag. Nat. Hist., ser. 2, t. 8, str. 202. 1913. Keratella cochlearis tecta Harring, Bull. Unit. Stat. Nat. Mus. vol. 81. 1918. Anuraea cochlearis var. tecta We be $\mathrm{r}$ et Mont et, Cat. d. Rot.

Jednym $\mathrm{z}$ wniosków $\mathrm{L}$ a u te n b orn'a był pogląd, że osobniki letnie Keratella cochlearis (G os s e) mają kolce tylne krótsze od zimowych. Odmienny wniosek W e s e n b e r g-L u n d'a ( raea cochlearis var. tecta ist die Hauptform des Winters") nie został przez cały szereg następnych autorów potwierdzony. Również i moje obserwacje nad zmiennością całoroczną Keratella cochlearis (Gosse) w jeziorze Chodeckiem przekonały mnie, że osobniki zimowe mają kolce tylne dłuższe od letnich. Podobne stosunki obserwowałem i w materjale poleskim, a mianowicie osobników o tak długich kolcach tylnych, jakie udało mi się zauważyć w jeziorze Chodeckiem zimą (var. macracantha $\mathrm{L}$ a ut e $n$ b or n), nie wykryłem w materjale letnim $z$ Polesia. Również i Bloedorn (1912) obserwował w Poznańskiem formy o kolcach dłuższych w zimie. $\mathrm{Zi} \mathrm{m} \mathrm{mer}{ }^{14}$ ) stwierdził w Odrze przewagę Keratella cochlearis var. tecta ( $\mathrm{G}$ oss e) nad innemi odmianami tego

13) $\mathrm{H}$ u be r, G. Monographische Studien im Gebiete der Montigglerseen (Sïdtirol) mit besond. Berïcksichtigung ihrer Biologie. Arch f. Hydrob. T. 1. str. $1-81,123-216,1905$.

14) $\mathrm{Z}$ i mme r, C. Das tierische Plankton der Oder. Forsch. Biol. Stat. Plön, Stuttgart, vol. 7, (1899). 
gatunku w ciągu lata (od lipca do września). Wrotek ten został stwierdzony $u$ nas $w$ szeregu rzek, a mianowicie: w Jasiołdzie, Niemnie (i jego dopływach), Muchaczu przez V or on kov a (1907); Wiśle pod Gdańskiem przez L uck s'a (1912); Warcie (Bloedorn, 1912); Sołokiji przez Jakubskiego (1915); w Prypeci i Jasiołdzie był ponadto notowany przez $W$ isz niewskiego (1930). W moim materjale spotykałem formę tę w próbkach $z$ Piny (10 VII, 1913).

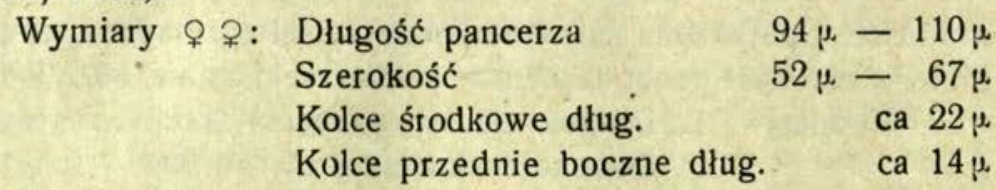

4. Keratella cochlearis ( $\mathrm{G}$ os s $\mathrm{e}$ ) var. irregularis $\mathrm{L}$ a u t e $\mathrm{n}$ born.

1900. Anuraea cochlearis var. irregularis L a te n bor n, Verh. Naturhist. Med. Ver. Heidelberg, N. F., T. 6, str. 431 , ryc. 3,4 i tabl. 10 , ryc. 19. 1918. Anuraea cochlearis (Gos se) var. irregularis $\mathrm{L}$. We be r et $\mathrm{M}$ o n tet, Cat d. Rot. str. 86.

Formę tę stwierdził w r. 1907 V or on k o v w swej pracy, dotyczącej wrotków litewskich. W Małopolsce do tej pory nie zauważona, mimo licznych poszukiwań systematycznych, przeprowadzonych w tej części ziem polskich. O ile mi wiadomo, nie była wogóle forma ta notowaną u nas w wodach płynących. W moim materjale spotykałem ją zarówno w rzece Pinie (10 VII, 1913), Kanale Ogińskiego (4 VIII, 1913), jak i jeziorze Wyganowskiem (4 VIII, 1913).

Wymiary \&: Długość ogólna pancerza $163 \mu$.

$\begin{array}{ll}\text { Szerokość } & 82 \mu \\ \text { Kolec tylny } & 63 \mu\end{array}$

5. Keratella cochlearis (Gos s e) var. irregularis f. angulifera $\mathrm{L}$ a u te $\mathrm{n}$ b or $\mathrm{n}$.

1900. Anuraea cochlearis var. irregularis $\mathrm{f}$. angulifera $\mathrm{L}$ a u t e $\mathrm{n}$ b o $\mathrm{rn}$, Verh. Naturhist.-Med. Ver. Heidelberg, N. F. T. 6.

Wrotka tego po raz pierwszy stwierdził na ziemiach polskich w r. $1915 \mathrm{~J}$ akubski. W wodach płynących forma u nas jeszcze nie spotykana. Znalazłem niewielką ilość egzemplarzy tej formy w próbkach, pochodzących z rzeki Piny (koło Konczyc) 10 VIII, 1913. 


\section{Keratella cochlearis ( $\mathrm{G}$ os s e) var. irregularis}

f. connectens L a u t e n born.

1900. Anuraea cochlearis var. irregularis f. connectens Lautenborn, Verh. Naturhist.-Med. Ver. Heidelberg, N. F., Tom 6.

Formę tę nową dla fauny polskiej znalazłem w próbkach, pochodzących $\mathrm{z}$ rzeki Piny (środek rzeki 10 VII, 1913; zalane brzegi koło Konczyc 10 VII, 1913).

\section{Keratella cochlearis ( $\mathrm{G}$ os $\mathrm{s}$ ) var. irregularis f. ecauda La ut en born.}

1900. Anuraea cochlearis var. irregularis f. ecauda L a te n b o rn, Verh. Naturhist.-Med. Ver. Heidelberg, N. F. t. 6, str. 434, tabl. 10, ryc. 20.

Forma ta po raz pierwszy zauważoną została na ziemiach polskich przez Jakubskiego (1915) w łasze Bugu. W rzekach polskich do tej pory nie obserwowana. Spotykałem ja zarówno w Pinie (środek rzeki, 10 VII 1913), Kanale Ogińskiego (4 VIII 1913), jak i jeziorze Wyganowskiem (4 VIII 1913).

\section{Keratella cochlearis (Gosse) var. hispida Lautenborn.} 1900. Anuraea cochlearis var. hispida La u t e n b o n, Verh. Naturhist.-Med. Ver. Heidelberg, N. F. T. 6 , str. 430 , tabl. 10 , ryc. $13-14$.

W obrębie szeregu "hispida" ("hispida-Reihe") do lat ostatnich nie były zauważone formy bez kolca tylnego. Dopiero w r. $1921 \mathrm{Ammon}^{15}$ ) znalazł niewielką ilość egzemplarzy tej odmiany, pozbawionych kolca tylnego, w jeziorze Federsee (Wirtenbergja). W Pinie nie udało mi się wyszukać Keratella cochlearis var. hispida f. ecauda A m mon, jednak niektóre osobniki posiadaly kolce tylne krótsze od dotychczas opisywanych (por. ryc. 1 i 2). Według obserwacji A m mo n’a (1921) długość kolca tylnego u var. hispida La ut. w jeziorach bawarskich wynosi najmniej $15 \mu$; w Pinie (10 VII 1913) natomiast zauważyłem formy o kolcach krótszych $(10-12 \mu)$. Analogicznie do Keratella cochlearis var. macracanta f. microcanta La ut. możnaby stwierdzoną przeze mnie formę nazwać Keratella cochlearis var. hispida

15) A m mo n, H. Zum Formenkreis von Ceratium hirundinella etc. Arch. f. Hydrob. T. 13 (1921). 
f. microcantha f. no v. jako formę łączącą zwykłą var. hispida $\mathrm{z}$ opisaną przez A m mo n'a (1921) bezkolcową formą tego szeregu.

Keratella cochlearis var. hispida La u t e n b o r n notowana już była z Polesia przez Voronkova (1909) i Wiszniewsk ieg o (1930).

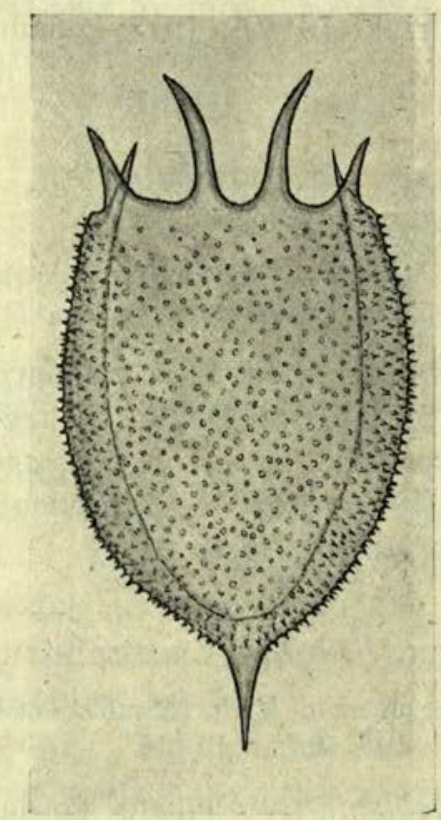

Ryc. 1. Keratella cochlearis var. hispida La u te $\mathrm{n}$ born.

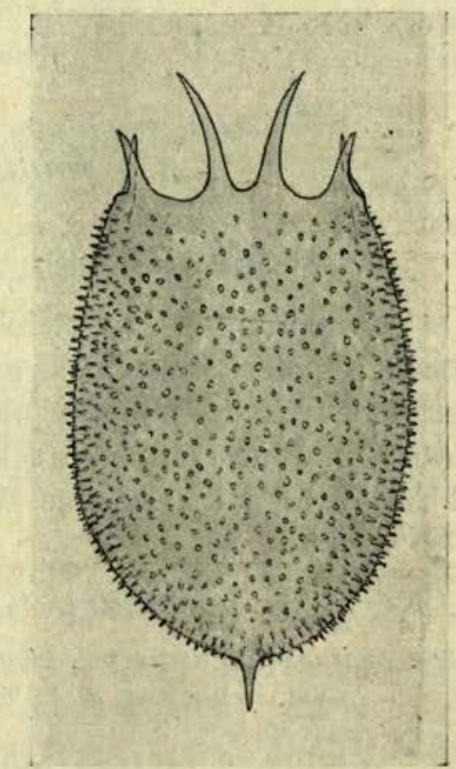

Ryc. 2. Keratella cochlearis var. hispida f. microcantha f. $\mathrm{n}$ ov.

Wymiary: 우 우 $\begin{aligned} & \text { Długość pancerza ogólna ca } 148 \mu \\ & \text { Szerokość " } \\ & \text { Kolec tylny } 10 \mu-12 \mu-20 \mu\end{aligned}$

9. Keratella cochlearis ( $\mathrm{G}$ os s e) var. leptacantha La ut en born.

1900. Anuraea cochlearis var. leptacantha Lauten $\mathrm{bor} n$, Verh. Naturhist. Med. Ver. Heidelberg. N. F. T. 6 s. 428 , ryc. $24-25$.

Forma ta, o ile mi wiadomo, nowa dla fauny polskiej. Pewna ilość osobników tej formy znalazłem w planktonie z rzeki Piny (10 VII 1913). 


\section{Keratella quadrata (M ü ll e r).}

1838. Anuraea aculeata $\mathrm{E}$ h re $\mathrm{n}$ berg. Die Infusionsthierchen als volkommene Organismen str. 508 , tabl. 62 , ryc. 14.

1908. Anuraea aculeata $\mathrm{E} \mathrm{h} \mathrm{r} \mathrm{b.} \mathrm{K} \mathrm{ră} \mathrm{t} \mathrm{s} \mathrm{chm}$ a r, Intern. Rev. Hydrobiol. T. 1 . str. $623-675$.

Sezon, w którym podany wyżej gatunek wrotka występuje w planktonie, jest różny, zależnie od charakteru zbiornika (p. H e u$\mathrm{sch}$ e $\mathrm{r}^{16}$ ). W wodach płynących $\mathrm{u}$ nas Keratella quadrata $\mathrm{Ehrb}$. była stwierdzona w Jasiołdzie, Niemnie i jego dopływach przez Voronkova (1907), w Wiśle pod Gdańskiem przez Lucks'a (1912), w Bugu przez Jakubskiego (1915), W is zniewski (1930) spotykał ją w Pinie, Jasiołdzie i Prypeci. Przeze mnie spotykana w rzece Pinie (środek rzeki, 10 VII 1913 i między zaroślami grzybieni i grążeli na prawym brzegu, kuło Potapowicz). Wymiary: $\subsetneq$ Długość pancerza $200 \mu$ Szerokość $80 \mu$ Długość kolców tylnych $60 \mu$. . $\quad n \quad$ przednich $38 \mu$

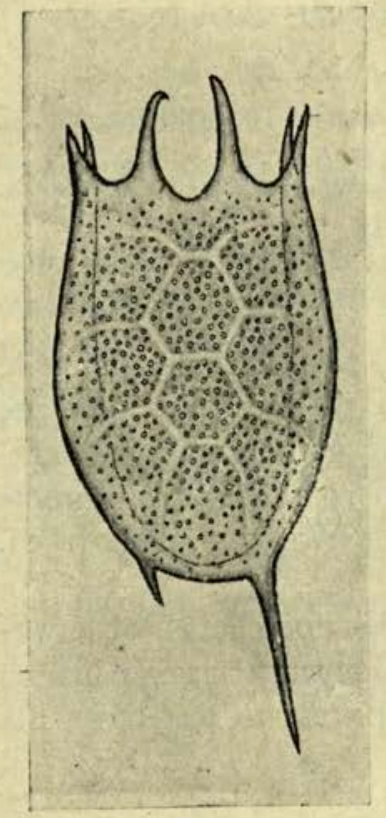

11. Keratella quadrata (Mülle r) var. valga $\mathrm{E}$ hrenberg.

1838. Anuraea valga Ehren berg. Die Infusionsthierchen als vollkommene Organismen str. 508 , tabl. 62 , ryc. 15 .

1918. Anuraea aculeata var. valga Ehren b., We ber et Montet, Cat. d. Rot. str. 79.

Wrotek ten nie był jeszcze wyróżniony $u$ nas w wodach płynących. Spotykałem go $w$ rzece Pinie (lewy brzeg między trzcinami, 18 VII 1913) i w jeziorze Wyganowskiem w planktonie 4 VIII 1913.

Ryc. 3. Keratella quadrata var. valga $\mathrm{Eh}$ re $\mathrm{nberg}$.

${ }^{16)}$ He u s cher, H. Das Zooplankton des Zürichsees mit besonderer Berïcksichtigung der Variabilität einiger Planktoncladoceren. Arch. f. Hydrobiol. u. Planktonkunde. T. XI, z. 1, 1916. 
Wymiary: 우 Długość pancerza $178 \mu$

Kolec środkowy przedni $30 \mu$.

Kolec tylny I $44 \mu$.

, $\quad$ II $10 \mu$.

12. Keratella quadrata (M ülle r) var. brevispina $G$ os $\mathrm{st}$

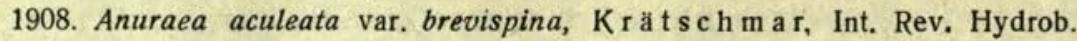
T. 1 , str. 629 , ryc. 9 .

1918. Anuraea aculeata var. testudo (E h re n b.), W eb e r et Mo n te t, Cat. d. Rot. str. 80 .

Forma ta występuje głównie w bagnach i kałużach. W rzece Bugu znalazł ją w r. $1915 \mathrm{~J}$ a kubs ki.

W moim materjale spotykałem tę odmianę w rzece Pinie (między trzcinami, 18 VII 1913). Wiszniewski (1930) notuje Keratella quadrata var. brevispina (Ehrenb.) $\mathrm{z}$ bagien poleskich.

13. Keratella quadrata (M ü1le r) var. curvicornis Ehrenberg.

1886. Anuraea curvicornis, E. Huds on and Goss e, The Rotifera, Vol. 2, str. 122 , tabl. 29 , ryc. 9,9 a.

1908. Anuraea aculeata var. curvicornis, $\mathrm{K} \mathrm{rats} \mathrm{ch} \mathrm{mar}$, Int. Rev. Hydrobiol. T. 1 , str. 629 , ryc. 11

1918. Anuraea aculeata var. curvicornis, We b e $\mathrm{r}$ et $\mathrm{M}$ o $\mathrm{n}$ te $\mathrm{t}$, Cat. d. Rot str. 81,82 .

Lucks (1912) uważał tę odmianę za oddzielny gatunek, podobnie jak var. serrulata We ber. O ile tę drugą odmianę niektórzy autorzy uważaja za samodzielny gatunek, to var. curvicornis pozostała w "Synopsis“ Harring'a (1913) w obrębie gatunku Keratella quadrata (por. również We ber i Montet, 1918).

W rzekach u nas forma ta nie była dotychczas obserwowaną. Znalazłem ją w próbkach, pochodzących $z$ lewego brzegu rzeki Piny (koło Konczyc, 18 VII 1913). Forma ta jest nową dla fauny wrotków Polesia. 
Dane dotychczasowe, zestawione w notatce Voronkova (1907) i przyczynku Wiszniewskiego (1930) a dotyczace występowania wrotków z rodzaju Keratella B ory de St. V inc e nt na Polesiu zostają wzbogacone powyższym spisem o 9 następujących form: * $K$. cochlearis var. macracantha f. microcantha $\mathrm{L}$ a u te n b., K. cochlearis var. irregularis $\mathrm{L}$ a u ten b., K. cochlearis var. irregularis f. angulifera $\mathrm{La}$ ute $\mathrm{n} \mathrm{b} .,{ }^{*} K$. cochlearis var. irregularis f. connectens $\mathrm{L}$ a u te $\mathrm{n} \mathrm{b} ., \quad K$. cochlearis var. irregularis f. ecauda La ut en b., " $K$. cochlearis var. hispida f. microcantha f. nov. K. cochlearis var. leptocantha La ut en b., K. quadrata var. valga Ehrenb., K. quadrata var. curvicornis Ehrb. $Z$ tych 4 formy oznaczone gwiazdkami są nowe dla fauny polskiej, a $K$. cochlearis var. hispida f. microcantha forma po raz pierwszy wyróżnioną.

\section{ZUSAMMENFASSUNG}

Im Material, das während des Sommers (Juli, August 1913) in Pina-Flusse, Ogiński-Kanal und Wyganowski-See gesammelt wurde, hat der Verfasser 13 Formen von Rotatorien aus der Gattung Keratella Bory de St. Vincent verzeichnet. Unter diesen waren 9 folgende Formen für Polesie neu: ${ }^{*} K$. cochlearis var. macracantha f. microcantha $\mathrm{L}$ a u ten born., K. cochlearis var. irregularis $\mathrm{f}$. angulifera $\mathrm{La}$ ute $\mathrm{nb}$., * $K$. cochlearis var. irregularis f. connectens $\mathrm{L}$ a u t e $\mathrm{n}$ b., K. cochlearis var. irregularis f. ecauda La u ten b., *K. cochlearis var. hispida f. microcantha f. nov. ${ }^{*} K$. cochlearis var. leptocantha La ut e n b., K. quadrata var. valga $\mathrm{Eh \textrm {rb }}$., $K$. quadrata var. curvicornis $\mathrm{Eh \textrm {rb }}$. Es finden sich darunter 4 (mit Stern versehene) Formen, die eine Neuheit für die polnische Fauna bilden. Ausserdem benachrichtigt der Verfasser über einige Exemplaren von $K$. cochlearis var. hispida Lautenb. die einen sehr kurzen Hınterdorn (f. microcanta n. f.) haben (Fig. 2). 